1050

\section{APPROACH OF WEIGHT RECOVERY AND WATER-PROTEIN-CALORIES ADMINISTRATION IN CRITICAL ILL PREMATURE NEONATES DURING EARLY PARENTERAL NUTRITION}

\author{
E.C. Urbina1, M.C.P. Fátima², J.C.S. Herrera ${ }^{3}$
}

${ }^{1}$ Neonatology Care Unit, ${ }^{2}$ Pediatrics Unit, ${ }^{3}$ Pediatric Oncology Unit, Mexican Social Security Institute, Cd. Obregón, Mexico

Aim: Evaluate weight recovery and water, proteins and calories administration in critical ill premature neonates during early parenteral nutrition

Methods: We designed a randomized clinical essay with a group of premature newborn children's enter in neonatal care unit of a regional concentration hospital. Agreement two groups were formed using time parenteral and oral nutrition beginning (I=early, II=last). We evaluate weight at born, gestational age, time - in days- recovery weight to birth, proteins and calories amount administration with associated complications. They were joined by gestational age, weight, length and gender. Analysis data was by non parametric statistics.

Results: Took part 49 premature neonates throughout 23 months of study. Average gestational age was 29.5 weeks and $1138 \mathrm{gr}$ in weight. Statistical difference $(p=0.05)$ was founded in faster and more weight recovery determined by group I. By same way study showed difference $(p=0.04)$ in first and third week follow-up determined by experimental group in amount of fluids, and from first week to end (4 week) in caloric $(p=0.000)$ and proteins $(p=0.000)$ administration. Experimental group determined difference in more infectious complications $(p=0.09)$.

Conlusions: Early beginning of parenteral nutrition seems favorable to recovery birth weight in premature neonates critically ill, avoiding by this way, caloric and proteins lacking with infection as the most important complication.

Key words: parenteral nutrition, premature, critical ill children, neonates

\section{AWARENESS, PRACTICES AND BENEFITS OF BREAST FEEDING IN ISRA UNIVERSITY HOSPITAL (PAKISTAN)}

\author{
A.A. Baig \\ Isra University, Hyderabad, Pakistan
}

Introduction: Breastfeeding has always been an important issue worldwide; several studies have been done. We have also done such a study in Isra University Hospital.

Objectives: To determine knowledge about optimum breast feeding practices and to evaluate the awareness of breast feeding through demographic parameters.

Determine the causes of failure of breast feeding among mothers.

\section{Study design: Prospective Study}

Results: Breast feeding was initiated by $89.33 \%$ of mothers. $10.67 \%$ of mothers, who failed to breastfeed their babies reason being no milk production. $62.69 \%$ of mothers had no any problem or difficulty due to breast feeding. $53.33 \%$ of females were found to be aware of all the optimum breast feeding practices recommended by $\mathrm{WHO}$.

Discussion: As per our study 114 females (76\%) practiced Colostrum, but exclusive breast feeding was conducted only by $6(4 \%)$ of females. While same study was conducted in Pakistan according to UNICEF $16 \%$ of babies in Pakistan were found to be exclusively breast fed. $10 \%$ of our studied females did not breastfeed their babies out of them 8 women; $50 \%$ had problems in milk production. UNICEF found that in New York, USA; $54 \%$ of the women who used breast milk substitutes said they were unable to produce enough breast milk. $18 \%$ used formula because they had to return to work or school, and $11 \%$ said that the baby refused the breast.

Conclusion: According to our study Illiterate females and house wives were breast feeding more as compared to economically well-off mothers. 